\title{
Low cervical chordoma: case report
}

\author{
Servet Inci, Selçuk Palaoğlu, Behsan Önol and Aykut Erbengi \\ Department of Neurosurgery, School of Medicine, University of Hacettepe, Ankara, Turkey
}

\begin{abstract}
We report a case of a 32-year old woman with radicular symptoms associated with a low cervical chordoma. According to our knowledge this is the 10th case of low cervical chordoma reported in the literature.
\end{abstract}

Keywords: cervical spine; chordoma

Chordoma is a rare malignant tumour arising from the remnants of the embryonic notocord. Approximately $85 \%$ of all cases of chordoma occur in the sacrum or in the cranial base. Involvement of the cervical thoracic and lumbar spine is uncommon, occurring in only $15 \%$ of cases. ${ }^{-4}$ Involvement of the lower cervical spine $(\mathrm{C} 5, \mathrm{C} 6, \mathrm{C} 7)$ is very rare. To our knowledge, only nine cases of lower cervical chordoma have, up to 1995, been reported in the literature. We report a case of a 32 year-old woman with a chordoma of the fifth cervical vertebra. Besides the rarity of such a case, the surgical technique applied is noteworthy.

\section{Case report}

A 32-year old female was admitted to our hospital with progressive right arm pain of 2 month's duration. The physical examination was unremarkable and disclosed no evidence of systemic disease. Neurological examination revealed slight weakness of the right biceps and slight hypoesthesia over the fifth and sixth cervical dermatomes on the right side. There was no evidence of spinal cord involvement. The routine laboratory studies were all within normal limits. Plain X-ray films of cervical spine demonstrated only tracheal displacement anteriorly. There was no collapse of any cervical vertebra. Computed tomographic scan showed the destruction of the C5 vertebral body on the right side. T1-weighted images of MRI in the sagittal plane showed an anterior soft tissue mass at the C5 level (Figure 1) with low signal intensity which displaced the trachea anteriorly. The vertebral body of C5 was also involved, as it exhibited decreased signal intensity in comparison with normal vertebral bodies. The intervertebral discs appeared to be intact. A technetium 99 methylene diphosphonate bone scan showed only increased activity in the $\mathrm{C} 5$ vertebrae. A tuberculin skin test was negative. Our preoperative diagnosis was of a metastatic tumour.

In January 1995, she was operated on by an anterior approach. When the longus colli muscles

Correspondence: Dr Servet Inci Emek Mah., 4. Cad., No: 70/8 Ankara, Turkey were dissected, the lesion was visualized. The macroscopic appearance of the lesion was a tumour with a nodular but smooth surface of greyish-white colour. The bulk of this exophitic tumour was totally excised. The frozen section diagnosis was chordoma. Subsequently, detailed histological study showed that the tumour was well encapsulated by a thick fibrous capsule and lobulated by fibrous stands. The lobules were composed of vacuolated physaliphrous cells containing variable amounts of intracytoplasmic mucin, embedded in lakes of extracellular mucin (Figure 3). Practically the whole corpus of C5 vertebra was involved. Therefore, a total corpectomy was carried out and then a C4-5 and C5-6 discectomy were performed. The spinal dura was intact. Right iliac bone grafting, and C4-C6 anterior spinal fixation with a titanium plated $\left(\right.$ Synthe ${ }^{\mathbb{R}}$ ) was done (Figure 2). The patient tolerated the operation well and was referred for radiotherapy to treat any possible residual tumour. A total of $5600 \mathrm{cGy}$ (200 cGy/Day) radiotherapy was given. The most recent follow-up examination was performed in November 1995, and her neurological state was entirely normal.

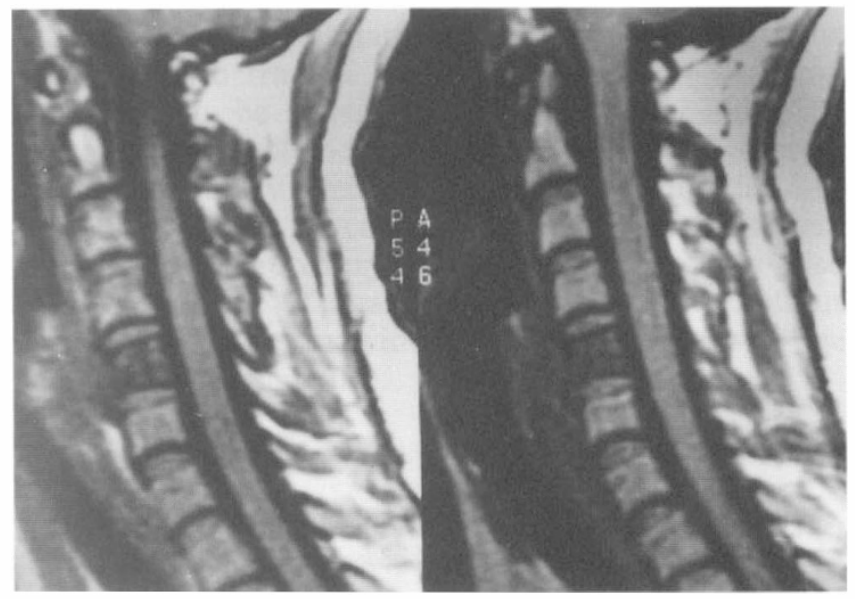

Figure 1 Parasagittal magnetic resonance image (T1weighted) shows a low intensity tumour at the C5 level 


\section{Discussion}

The notochord is the embryonic precursor of the vertebral column. It first appears in the 4 th week of human embryonic life and regress by the 7 th week to be enveloped and replaced by the mesodermal elements that form the vertebra. ${ }^{1}$ It is believed that chordomas arise from persistent remnants of these notochordal

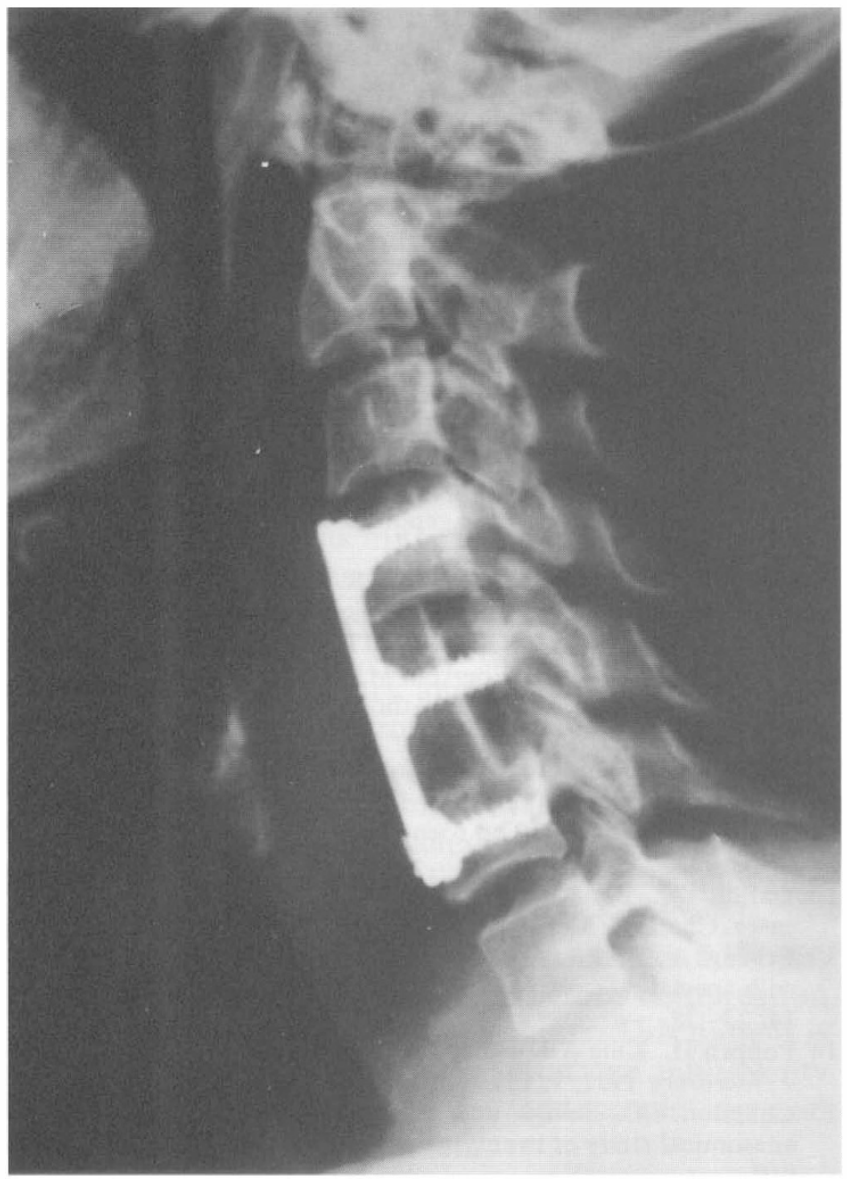

Figure 2 Postoperative lateral radiograph of the patient, showing the bone graft and titanium plate cells. $^{3-5}$ These tumours therefore usually occur in the midline, extending from the clivus to the sacrum. Rarely, the tumour presents off the midline such as in the transverse process of a vertebra. ${ }^{6}$

Chordomas generally occur in late middle age, during the fifth and sixth decades. However, they can occur at any age. Becker et al reported a chordoma of the clivus in a 10 month-old patient. ${ }^{7}$ Most recently Coffin et al also described a chordoma of the thoracic vertebra in a one month-old infant. ${ }^{8}$ There is a male preponderance of up to $2: 1$ in many series. ${ }^{1,9}$ Chordomas are grossly lobulated, soft, and grayish in appearance. They are well demercated in soft tissue but possess elusive margins in bone. ${ }^{1}$ They are usually slow growing but locally aggressive tumours. Metastases from chordoma have been reported to lung, lymph nodes, bone, skin and brain. $^{2,4,5,8}$ The usual radiological findings in chordomas of the vertebra are destructive or lytic lesions with occasional sclerotic changes. ${ }^{1,3}$ Calcifications of the soft tissue mass occurs in $15-18 \%$ of cases. ${ }^{1,3} \mathrm{MRI}$ should be considered the radiological study of choice for the diagnosis of chordomas, providing better

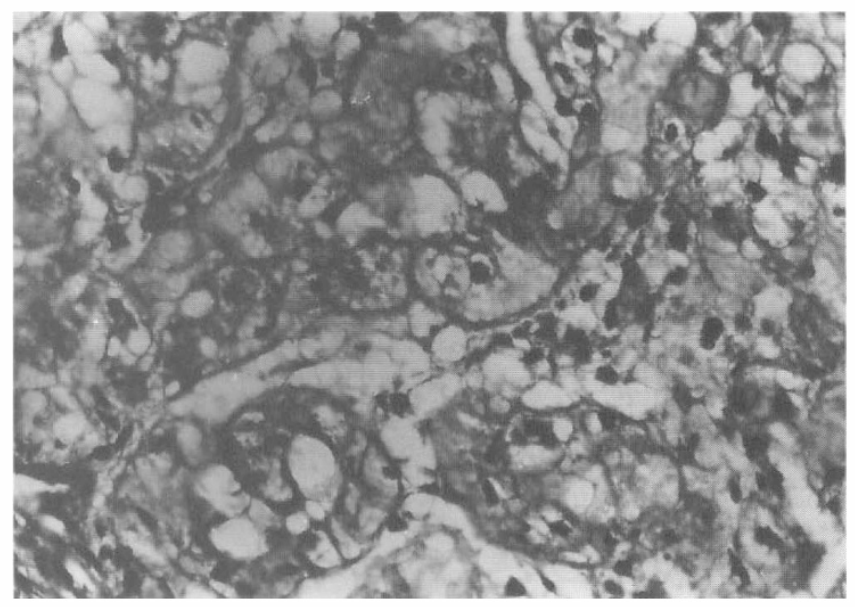

Figure 3 Photomicrograph of the pathological specimen showing the characteristic features of a chordoma $(\mathrm{HE}, \times 40)$

Table 1 Previously reported cases of low cervical chordomas

\begin{tabular}{|c|c|c|c|c|}
\hline Author and year & Sex and age & Location & Treatment & Follow-up \\
\hline \multirow{2}{*}{ Poppen and King, $1952^{14}$} & $\mathrm{M} / 30$ & $\mathrm{C} 5$ & Surgery & No recurrence in 9 years \\
\hline & $\mathrm{F} / 60$ & C6-C7 & Surgery, RT & Recurrence at 9 months \\
\hline Congdon, $1952^{15}$ & $\mathrm{~F} / 18$ & $\mathrm{C} 7$ & Surgery & Died, after 13 months \\
\hline Sennett, $1953^{10}$ & $\mathrm{M} / 66$ & $\mathrm{C} 5-\mathrm{C} 6$ & Surgery, RT & No recurrence in 6 months \\
\hline Pinto et al $1975^{14}$ & $\mathrm{~F} / 37$ & $\mathrm{C} 5-\mathrm{C} 6$ & Surgery & $?$ \\
\hline \multirow[t]{2}{*}{ Firooznia et al $1976^{3}$} & $\mathrm{~F} / 37$ & $\mathrm{C} 5-\mathrm{C} 7$ & Surgery, RT & Recurrence at 3 years \\
\hline & $\mathrm{F} / 61$ & $\mathrm{C} 4-\mathrm{C} 5$ & Surgery & No recurrence in 6 years \\
\hline \multirow[t]{2}{*}{ Coffin et al $1993^{8}$} & $\mathrm{~F} / 17$ & $\mathrm{C} 6-\mathrm{C} 7$ & Surgery & ? \\
\hline & $\mathrm{M} / 2.5$ & C7-T1 & Surgery & $?$ \\
\hline Present case (1995) & $\mathrm{F} / 32$ & $\mathrm{C} 5$ & Surgery, RT & No recurrence in 6 months \\
\hline
\end{tabular}


delineation of soft tissue tumour extension, adherence or invasive or paravertebral structures and of the site of origin of these tumours and is better than CT. In addition, multiplanar images are obtained by MRI which are especially helpful for planned surgery. The differential diagnosis of these tumours includes metastatic tumours, chondroma and chondrosarcoma. $3,4,10$

The cervical spinal area is a rare primary site of the chordomas. In the review by Utne and Pugh of all cases of chordoma reported by 1955 , there were 53 cervical chordomas among 1271 occurring at all sites (a $4.1 \%$ overall incidence). ${ }^{11}$ In the large series of Dahlin from the Mayo Clinic, approximately $7 \%$ of the chordomas occurred in the cervical lesion. ${ }^{12}$ In the recent report from our department, this ratio was $11.7 \%{ }^{13}$ Sundersan et al reported five cervical tumours in their series of 54, which included 36 sacrococcygeal, 11 lumbar and two thoracic of vertebral column origin. ${ }^{1}$ Cervical chordomas usually occur in the second cervical vertebra although any upper cervical vertebra may be involved. To our knowledge, only nine cases of lower cervical (C5, C6, C7) chordoma have been reported in the literature, up to $1995^{5,8,10,14-16}$ These nine cases are shown in Table 1 .

Local pain without any neurological sign is a common presenting complaint and the diagnosis is often not made until the patient develops signs of nerve root compression from a cervical chordoma. Signs of myelopathy may occur as a late feature. In upper cervical chordomas, anterior extention of the tumour usually occurs, causing dysphagia and difficulty in breathing. ${ }^{1,4,17}$ Sundersan et al reported on five patients with cervical chordomas two of whom presented with retropharyngeal masses. ${ }^{1}$

These tumours are often very large and unresectable at the time of their discovery. Since they respond poorly to irradiation and chemotherapy, the only chance for cure is by complete surgical resection. Total resection for chordomas of the distal sacrum and coccyx may be curative. ${ }^{18}$ In contrast, radical resection of cervical chordomas is rarely successful because of severe anatomical constraints. In the past, the majority of these patients underwent very limited resection by a laminectomy. In our limited experience, the anterior approach is more suitable for low cervical lesions. Ample exposure for tumour excision is achieved by this approach. Following such resection, the stability of the cervical spine should be ensured with the use of a bone graft and a metal plate. Most recently an anterolateral approach to the cervical spine has also been described which allows dissection and mobilization of vertebral artery. ${ }^{19}$
As a result, we believe that (1) chordoma should be included in the differential diagnosis of solitary vertebral lesions with a paraspinal, soft-tissue mass in an adult patient, (2) MRI is the best modality in the assessment of vertebral chordomas and (3) radical surgery, if possible, is considered the treatment of choice for chordomas.

\section{References}

1 Sundersan N, Galicich JH, Chu FCH, Huvos AG. Spinal Chordomas. J Neurosurg 1979; 50: 312-319.

2 Rich TA, Schiller A, Suit HD, Mankin HJ. Clinical and pathological review of 48 cases of chordoma. Cancer 1985; 56: $182-187$

3 Mindell ER. Current concepts review chordoma. J Bone Joint Surg 1981; 63-A: 501-505.

4 Kamrin RP, Potanos JN, Pool JL. An evaluation of the diagnosis and treatment of chordoma. J Neurol Neurosurg Psychiat 1964; 27: $157-165$.

5 Firooznia $\mathrm{H}$ et al. Chordoma: Radiologic evaluation of 20 cases. AJR 1976; 127: 797 - 805 .

6 Kamal MF, Farah RG, Malkawi HM. Chordoma in a lumbar vertebral transverse process: A Cases report and review of the literature. Clin Oncol 1984; 10: $167-172$.

7 Becker LE, Yates AJ, Hoffmann HJ, Norman MG. Intracranial chordoma in infancy: Case report. J Neurosurg 1975; 42: $349-$ 352 .

8 Coffin MC, Swanson PE, Wick MR, Dehner LP. Chordoma in childhood and adolesence. A Clinicopathologic analysis of 12 cases. Arch Path Lab Med 1993; 117: 927 - 933.

9 Bjornsson J, Wold LE, Ebersold MJ and Laws ER. Chordoma of the mobile spine. A Clinicopathologic analysis of 40 patients. Cancer 1992; 71: 735-740.

10 Sennett EJ. Chordoma: Its roentgen diagnostic aspects and its response to roentgen therapy. AJR 1953; 69: 613-622.

11 Utne JR, Pugh DG. The roentgenologic aspects of chordoma. AJR 1955; 74: $593-608$.

12 Dahlin DC. Bone tumors. General aspects and data on 6221 cases. Charles Thomas: Springfield, Illinois, 1978, pp. 329-343.

13 Erbengi A, Tekkök IH, Açikgöz B. Posterior fossa chordomaswith special reference to transoral surgery. Neurosurg Rev 1991; 14: $23-28$.

14 Poppen JL, King AB. Chordoma: Experience with thirteen cases. J Neurosurg 1952; 9: $139-163$.

15 Congdon CC. Benign and malignant chordomas. A Clinicoanatomical study of twenty-two cases. Am J Path 1952; 28: 793 810

16 Pinto RS, Lin JP, Firooznia H, Lefleur RS. The osseous and angiographic features of vertebral chordomas. Neuroradiology 1974; 9: $231-241$

17 Shallat RF, Teakman MS, Nagle RC. Unusual presentation of cervical chordoma with long-term survival. J Neurosurg 1982; 57: $716-718$.

18 Stetner B, Gunterberg B. High amputation of the sacrum for extirpation of tumors: principles and technique. Spine 1978; 3: $351-366$

19 Sen C et al. Management of the vertebral artery in excision of extradural tumors of the cervical spine. Neurosurg 1995; 36: $106-$ 116 